\title{
Non-Noble Cobalt Tungstate Catalyst for Effective Electrocatalytic Oxidation of Borohydride
}

Aarti Tiwari, Vikram Singh, Tharamani C. Nagaiah*

Department of Chemistry, Indian Institute of Technology Ropar, Rupnagar, Punjab-140001, India.

E-mail: tharamani@iitrpr.ac.in 


\section{EXPERIMENTAL SECTION}

\section{Catalyst Preparation:}

Materials: $\mathrm{CoWO}_{4}$ was synthesized using hydrated cobalt chloride $\left(\mathrm{CoCl}_{2} .6 \mathrm{H}_{2} \mathrm{O} ; 98 \%\right.$, Alfa Aesar), hydrated sodium tungstate $\left(\mathrm{Na}_{2} \mathrm{WO}_{4} .2 \mathrm{H}_{2} \mathrm{O} ; \geq 99 \%\right.$, Sigma-Aldrich), hydrated trisodium citrate (TSC i.e. $\mathrm{Na}_{3} \mathrm{C}_{6} \mathrm{H}_{5} \mathrm{O}_{7} .2 \mathrm{H}_{2} \mathrm{O} ; 99 \%$, Alfa Aesar) and analytical grade ethanol ( $\geq 99 \%$, Merck Millipore) without further purification. The requisite solutions were prepared using Millipore water (12 M $\Omega$ ).

Synthesis: An aqueous solution of $2.9 \mathrm{~g}$ trisodium citrate (TSC, $10 \mathrm{mmol}$ ) was prepared in $70 \mathrm{~mL}$ deionized water to which $1.2 \mathrm{~g}$ of $\mathrm{CoCl}_{2}(5 \mathrm{mmol})$ was added under vigorous stirring for $30 \mathrm{~min}$. A $30 \mathrm{~mL}$ aqueous solution of $5 \mathrm{mmol} \mathrm{Na} \mathrm{WO}_{4}$ was prepared separately and then added dropwise to the previous mixture of $\mathrm{CoCl}_{2}$ and TSC under constant stirring which resulted in a pinkish clear solution after $2 \mathrm{~h}$ of stirring. Subsequently, this mixture was hydrothermally treated for $12 \mathrm{~h}$ in a teflon-lined autoclave at 200,220 and $250{ }^{\circ} \mathrm{C}$ respectively yielding solid $\mathrm{CoWO}_{4}$. The obtained product was thoroughly washed with deionized water followed by its 1:1 mixture with ethanol several times and then dried in an oven at $60^{\circ} \mathrm{C}$ overnight to obtain the $\mathrm{C}$ 200, C-220 and C-250 catalyst samples depending upon their temperature treatment.

\section{Physical Characterization:}

The as synthesized samples were structurally analyzed using powder X-ray diffraction (XRD) measurements in the $2 \theta$ range from 10 to $65^{\circ}$ over a PANalytical X'Pert Pro MPD instrument employing $\mathrm{Cu}$ Ka radiation as the X-ray source. Later surface elemental composition was determined using X-ray photoelectron spectroscopy (XPS) over PHI VersaProbe II spectrometer, operating at $15 \mathrm{kV}$ and $35 \mathrm{~mA}$ under ultrahigh vacuum with $\mathrm{Al} \mathrm{K} \alpha$ radiation source having energy $1486.6 \mathrm{eV}$ which yielded Co $2 \mathrm{p}$, W $4 \mathrm{f}$ and $\mathrm{O}$ 1s XP spectra. Morphological analysis was performed using field emission scanning electron microscopy (FESEM; ZEISS, ULTRA PLUS) and transmission electron microscopy (TEM) and high resolution TEM (HR-TEM) analysis was performed using FEI Tecnai (G2 F20) operating at $200 \mathrm{keV}$. The UV-visible analysis were recorded using the Shimadzu UV-2600 spectrophotometer by using $\mathrm{BaSO}_{4}$ as the standard reflectance sample.

\section{Electrochemical Studies:}

A single compartment electrochemical cell was used comprising of a three-electrode assembly where glassy carbon (GC) electrode served as working electrode, graphite rod was the counter electrode and $\mathrm{Hg} / \mathrm{HgO} / 1 \mathrm{M} \mathrm{NaOH}$ was the reference electrode (potentials converted to RHE scale). Electrochemical measurements were performed using a modular potentiostat/galvanostat (Autolab 302N) controlled by Nova 1.11 
software. Prior to any measurement it was ensured that the GC was polished to a mirror finish over Nylon polishing cloth (SM 407052, AKPOLISH) using alumina slurry of various grades (1, 0.3 and $0.05 \mathrm{~mm}$ grain size; Pine Instrument, USA). Subsequently, complete removal of the physisorbed alumina particles from the GC surface was ensured by thorough washing followed by ultrasonication in Millipore water (12 M $\Omega$ ). The catalyst slurry was prepared by homogeneously mixing $\mathrm{CoWO}_{4}$ with Vulcan carbon (30:70) in a granite mortar-pestle for over an hour from which $3.75 \mathrm{mg}$ was dispersed in $1.5 \mathrm{~mL}$ of solution prepared from a 1:25 ratio mixture of water-to-isopropyl alcohol. This catalyst dispersion was then homogenized by ultrasonicating for about 15-20 min. to give the desired catalyst slurry from which $20 \mu \mathrm{L}(50 \mu \mathrm{g})$ was drop-casted over the mirror polished GC electrode $(\varnothing 2 \mathrm{~mm}$ ) to result in a uniform thin layer coating. The borohydride oxidation experiments were performed in $\mathrm{N}_{2}$ purged $1 \mathrm{M} \mathrm{NaOH}$ electrolyte containing $30 \mathrm{mM} \mathrm{NaBH}_{4}$ reactant unless specified otherwise. All the potentials in the text have been converted to SHE scale for uniformity. The activity of all the three catalyst variants (C-200, C-220 and C-250) towards borohydride oxidation reaction (BOR) was subsequently assessed by performing cyclic voltammetry (CV) and chronoamperometric measurements.

The amount of $\mathrm{H}_{2}$ evolved during the measurement over C-220 catalyst was performed in an air-tight electrochemical cell wherein graphite paper $\left(0.09 \mathrm{~cm}^{2}\right)$ served as working electrode while being compiled with graphite rod counter and $\mathrm{Hg} / \mathrm{HgO} / 1 \mathrm{M} \mathrm{NaOH}$ reference electrode. Once the electrodes were safely positioned in the cell and the $30 \mathrm{mM} \mathrm{NaBH}_{4}$ dissolved in $1 \mathrm{M} \mathrm{NaOH}$ electrolyte was introduced, the electrochemical cell was initially degassed and then flushed with Ar environment which was thereafter maintained throughout the measurement. Before starting, 100 $\mu \mathrm{L}$ of $\mathrm{N}_{2}$ gas was introduced in the electrochemical cell and after $10 \mathrm{~min} ., 100 \mu \mathrm{L}$ gas sample was retrieved and analyzed by GC while being referenced against $\mathrm{N}_{2}$ for quantification. Subsequently, the working electrode was constantly polarized at -0.8 $\mathrm{V}$ to initiate BOR and determine the $\mathrm{H}_{2}$ evolved in the first step of BOR. Thereafter, $100 \mu \mathrm{L}$ gas samples were retrieved at $0,2,10,20,30,60,120$ and $180 \mathrm{~min}$. respectively and analyzed in GC to quantify the amount of $\mathrm{H}_{2}$ evolved (Figure $3 \mathrm{~d}$ and Table $\mathrm{S} 1, \mathrm{SI}$ ) per unit mass of C-220 catalyst. 


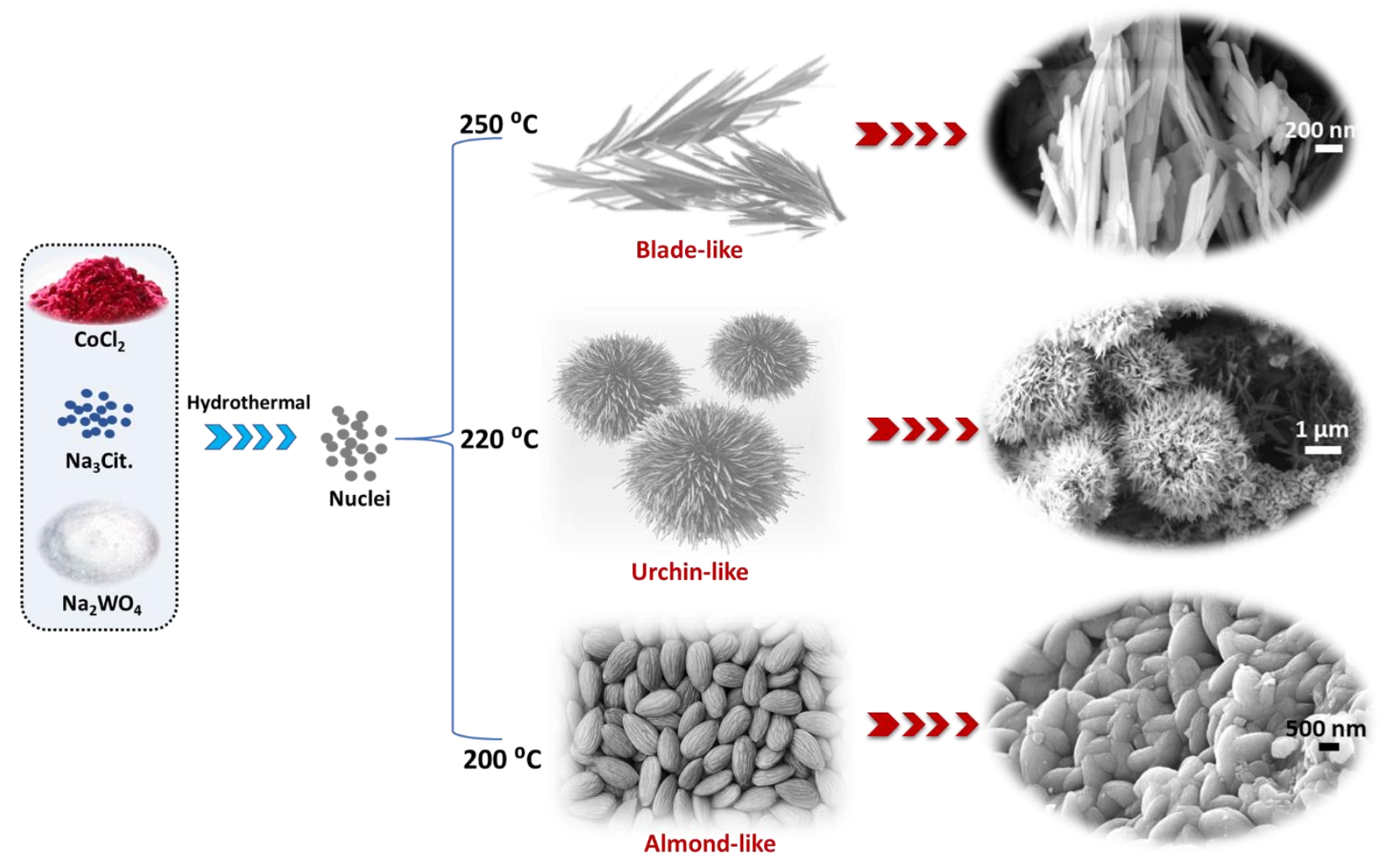

Figure S1. Schematic representation for the synthesis of shape-controlled $\mathrm{CoWO}_{4}$ by varying the synthesis temperature. 

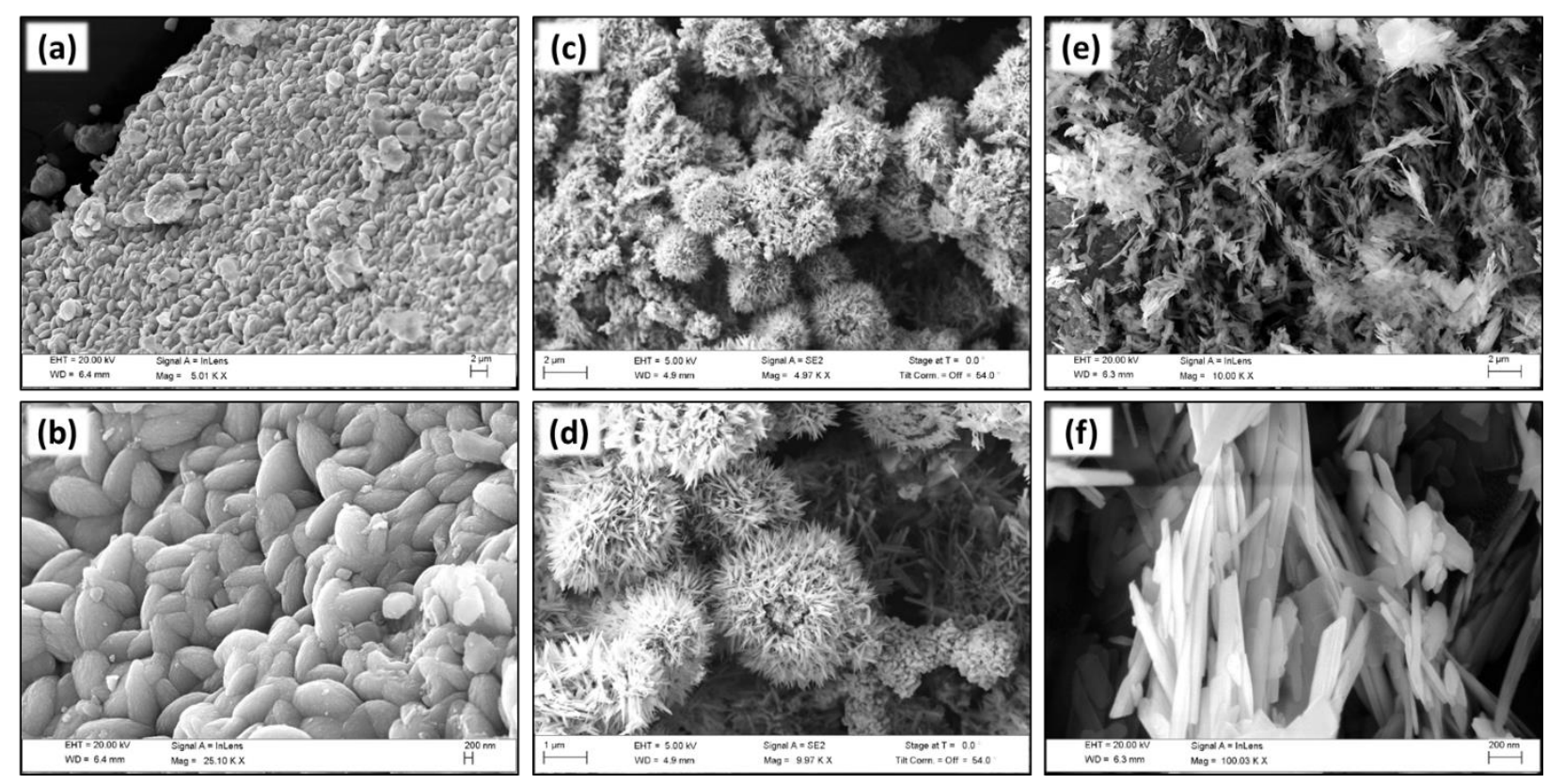

Figure S2. FE-SEM images of $\mathrm{CoWO}_{4}$ catalyst at various temperatures (a \& b) $200{ }^{\circ} \mathrm{C}$, (c \& d) $220^{\circ} \mathrm{C}$ and (e \& f) $250^{\circ} \mathrm{C}$. 


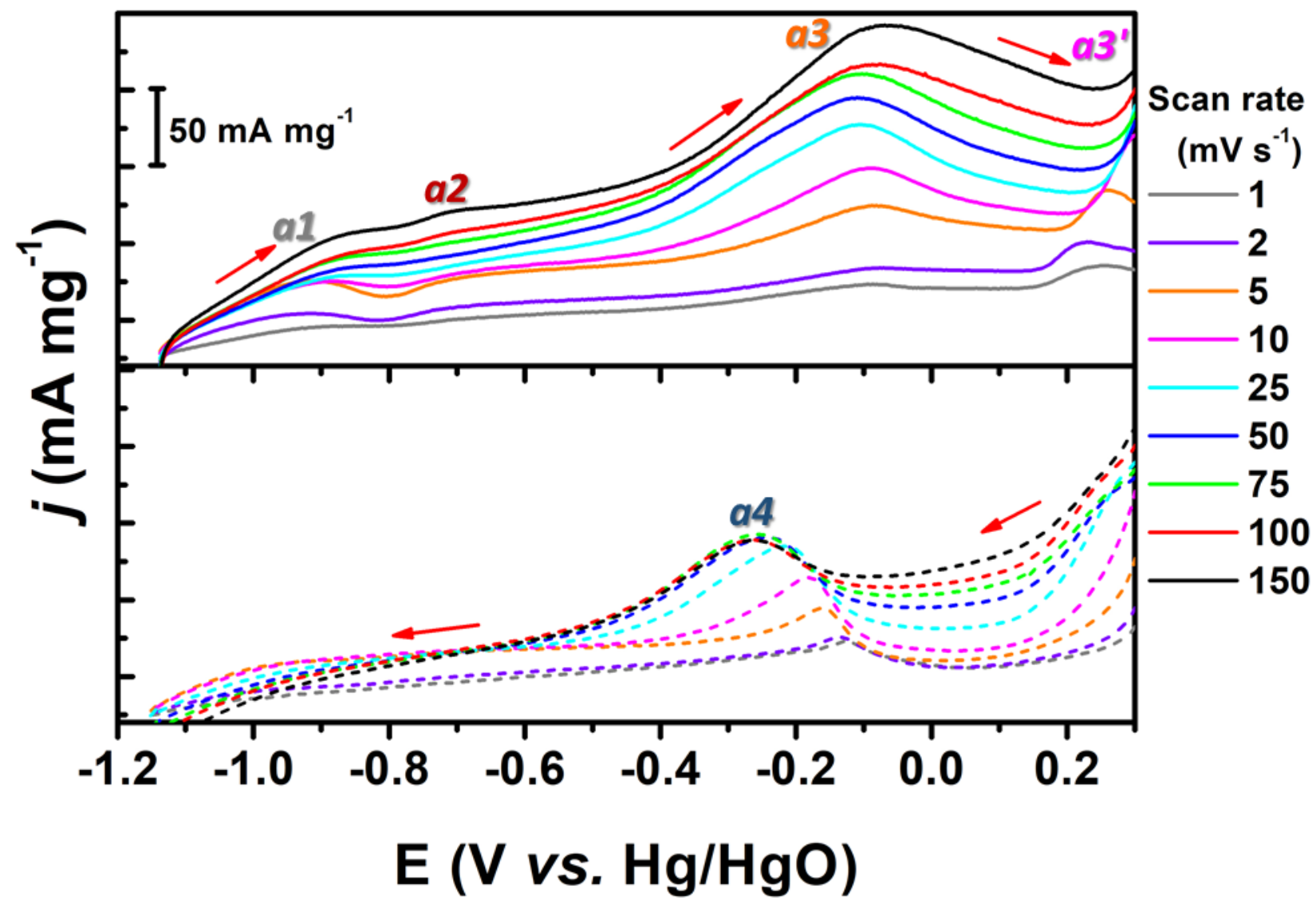

Figure S3. Scan rate variation from $1 \mathrm{mV} \mathrm{s}^{-1}$ to $150 \mathrm{mV} \mathrm{s}^{-1}$ for C-220 catalyst in $\mathrm{N}_{2}$ purged $30 \mathrm{mM} \mathrm{NaBH}$ prepared in $1 \mathrm{M} \mathrm{NaOH}$ electrolyte. CE: Graphite rod; RE: $\mathrm{Hg} / \mathrm{HgO} / 1 \mathrm{M} \mathrm{NaOH}$. 


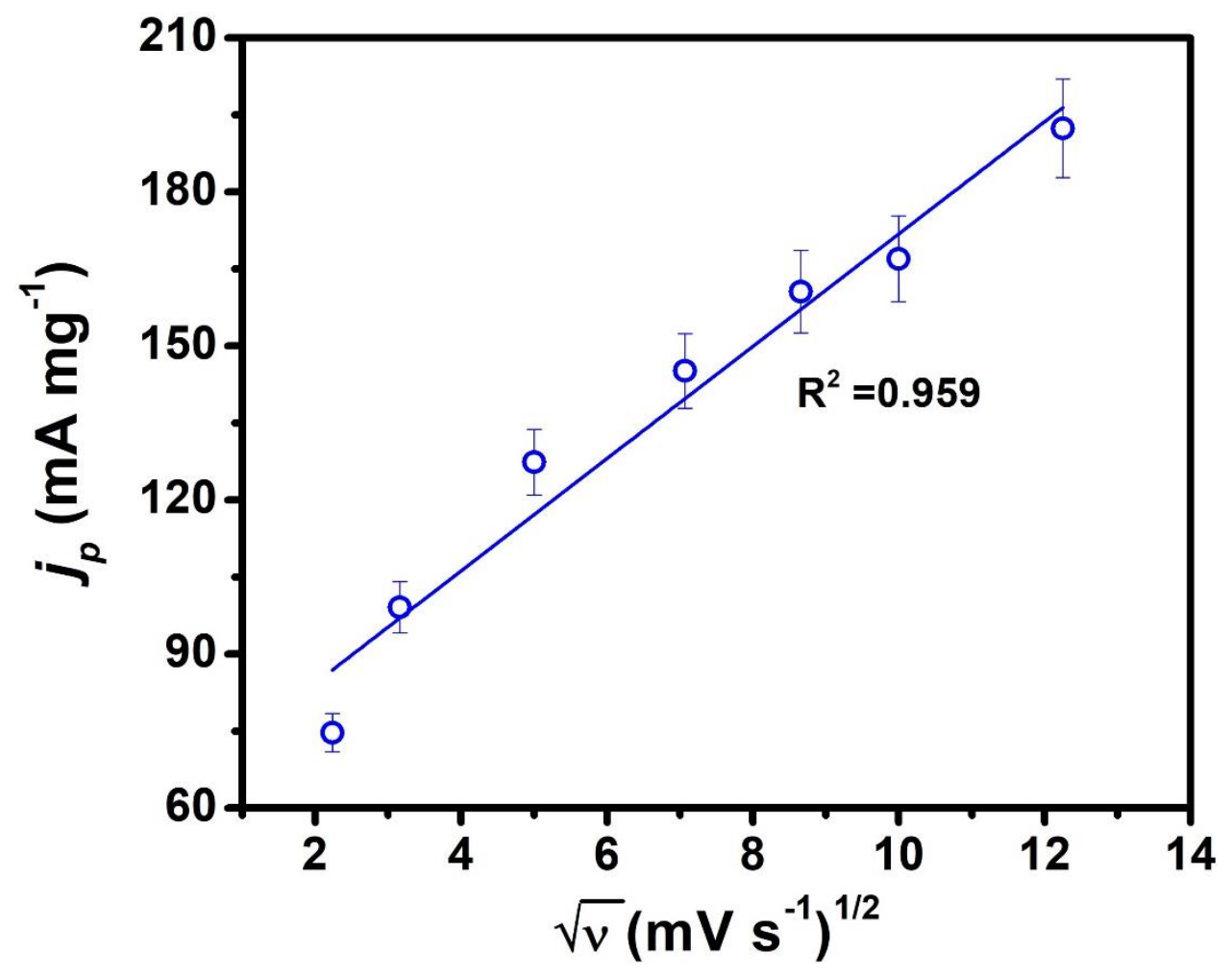

Figure S4. Scan rate dependence of the $a 3$ peak current density $\left(j_{p}\right)$ for the oxidation of $30 \mathrm{mM} \mathrm{NaBH}_{4}$ in $1 \mathrm{M} \mathrm{NaOH}$ over C-220 catalyst. 


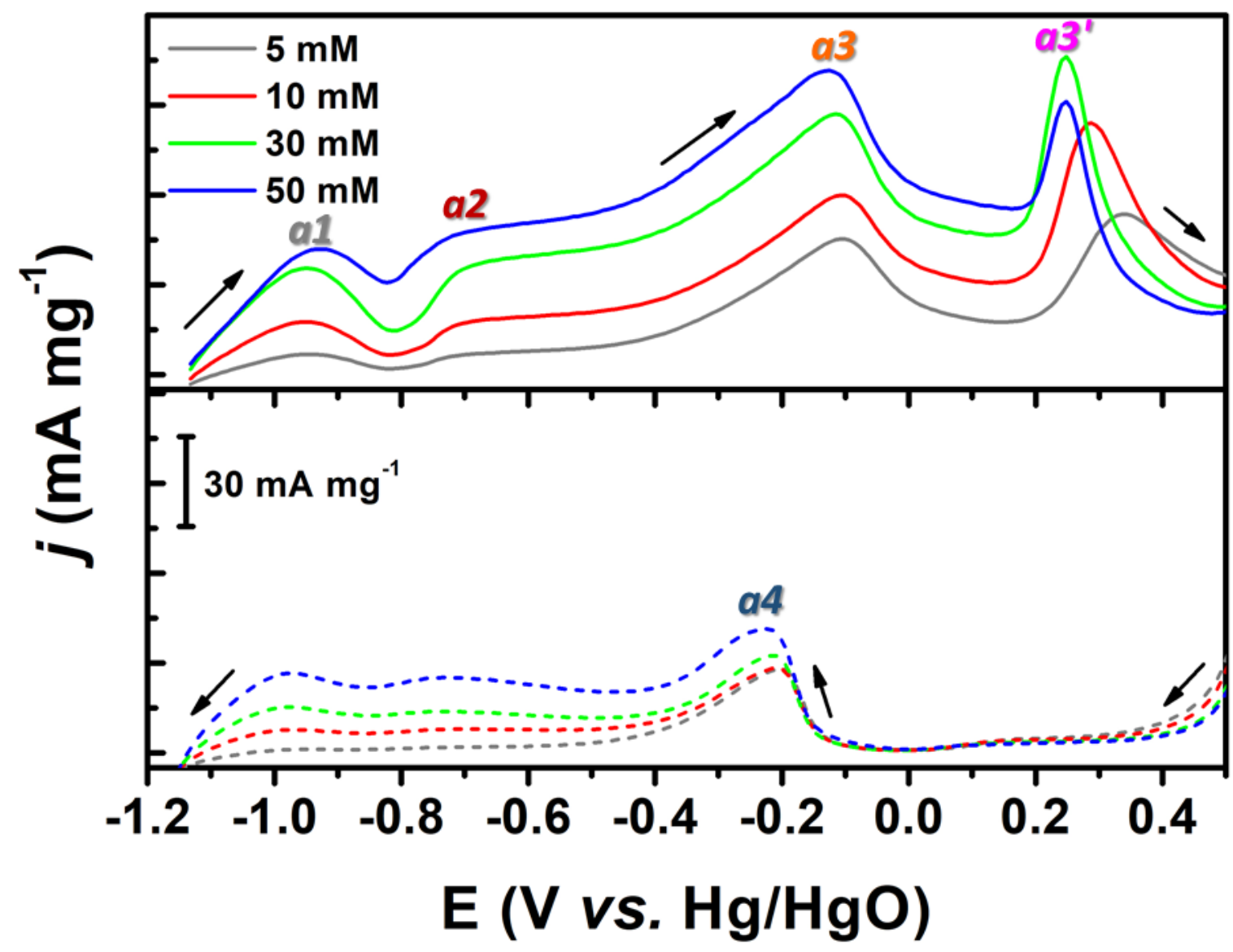

Figure S5. Cyclic voltammogram recorded for C-220 catalyst during concentration variation of $\mathrm{NaBH}_{4}$ from 5 to $50 \mathrm{mM}$ in $1 \mathrm{M} \mathrm{NaOH}$ electrolyte at $10 \mathrm{mV} \mathrm{s}^{-1}$. CE: Graphite rod; $\mathrm{RE}: \mathrm{Hg} / \mathrm{HgO} / 1 \mathrm{M} \mathrm{NaOH}$. 


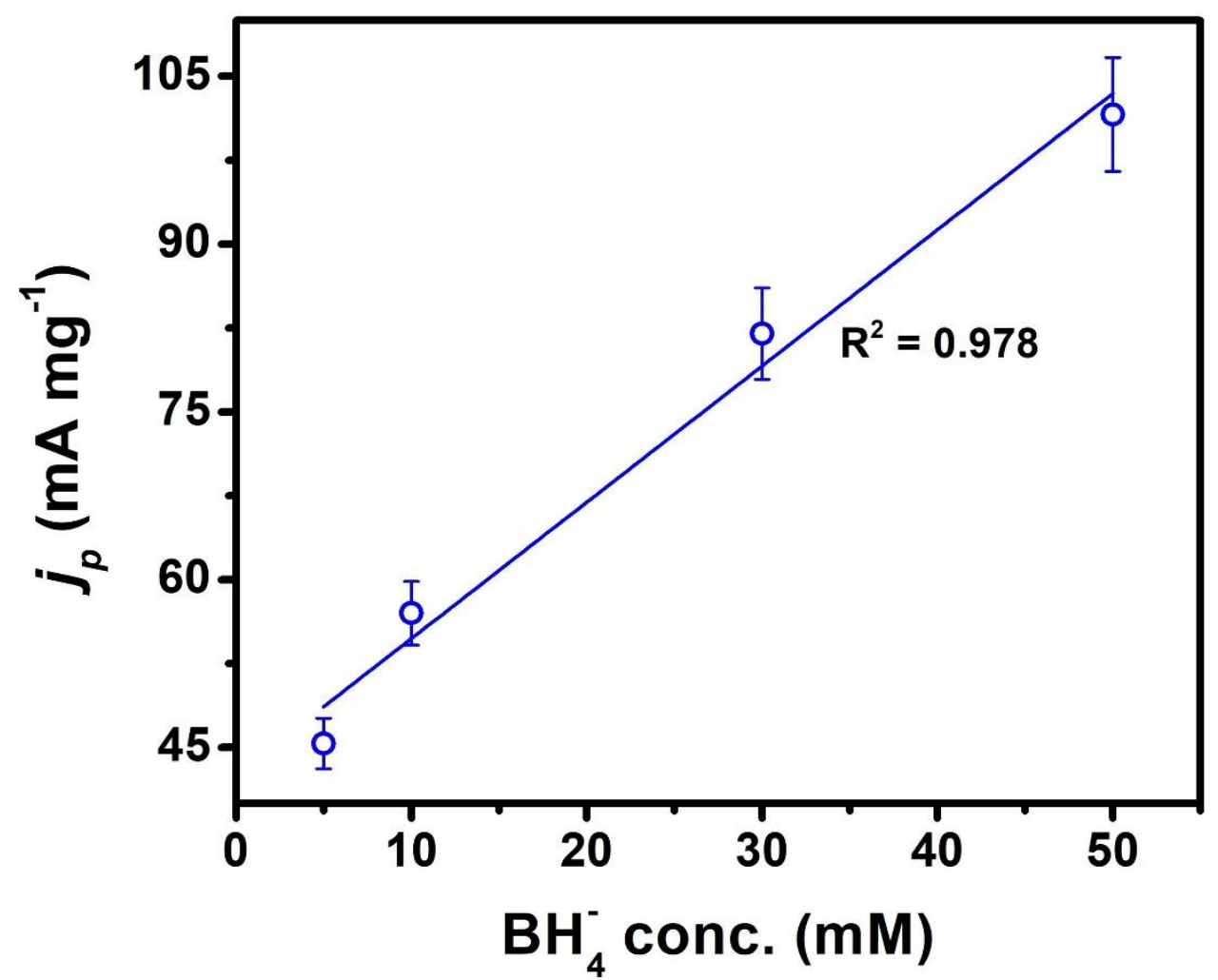

Figure S6. Effect of borohydride concentration over $a 3$ peak current density $\left(j_{p}\right)$ for the oxidation of $30 \mathrm{mM} \mathrm{NaBH}_{4}$ in $1 \mathrm{M} \mathrm{NaOH}$ over C-220 catalyst. 

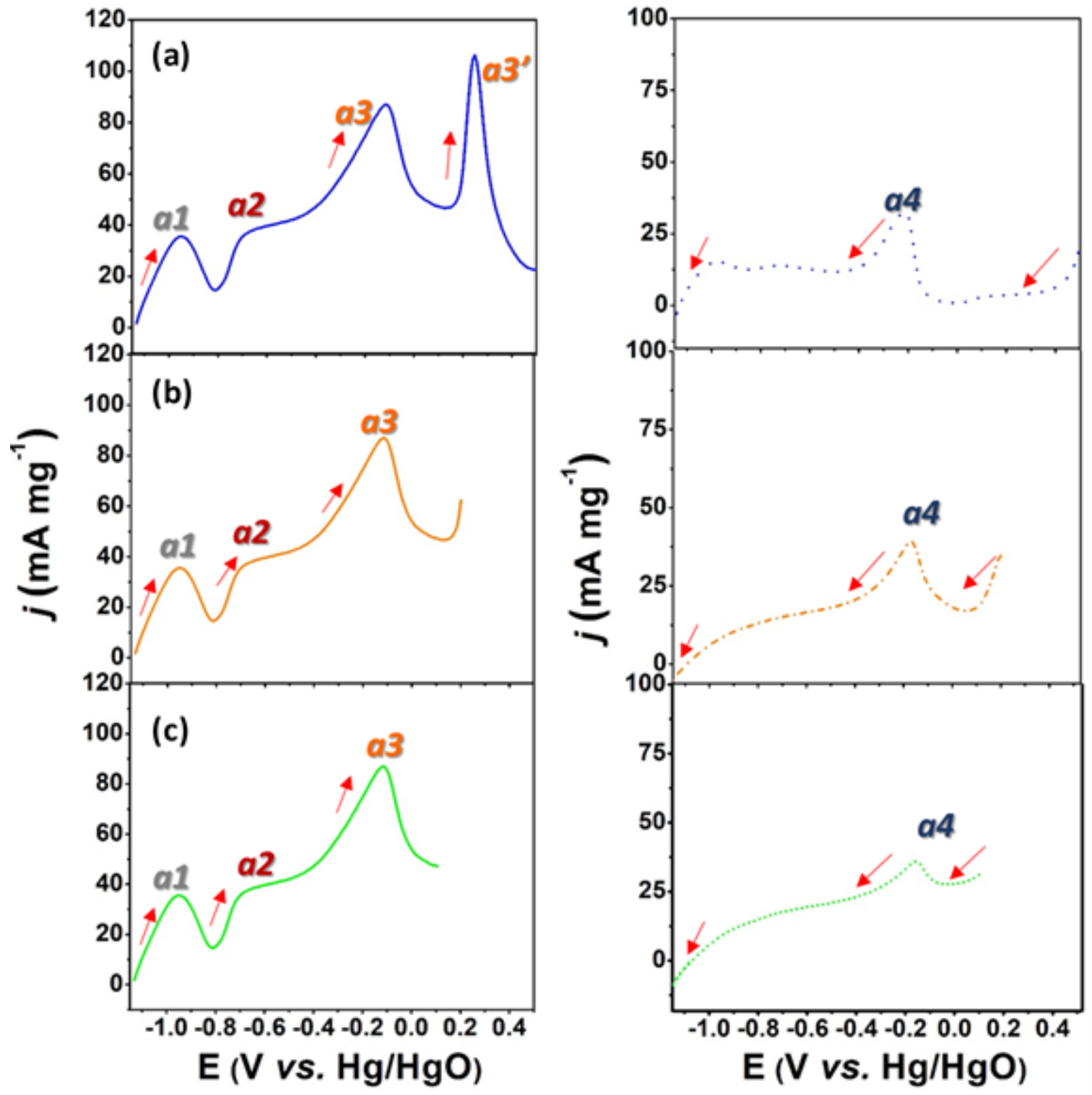

Figure S7. Cyclic voltammogram in three different potential ranges (a) from -1.15 to $0.5 \mathrm{~V}$ and (b) from -1.15 to $0.2 \mathrm{~V}$ and (c) 1.15 to $0.1 \mathrm{~V}$ at $10 \mathrm{mV} \mathrm{s}$ to confirm the origin of peak $a 4$ in $\mathrm{N}_{2}$-purged $30 \mathrm{mM} \mathrm{NaBH}_{4}$ prepared in $1 \mathrm{M} \mathrm{NaOH}$ electrolyte. CE: Graphite rod; RE: $\mathrm{Hg} / \mathrm{HgO} / 1 \mathrm{M} \mathrm{NaOH}$. 
Table S1: Gas chromatographic analysis of C-220.

\begin{tabular}{|c|c|c|}
\hline Time (min.) & $\mathbf{H}_{\mathbf{2}}$ volume $(\boldsymbol{\mu L})$ & Mass specific $\mathbf{H}_{\mathbf{2}}\left(\boldsymbol{\mu} \mathbf{~ m g}^{-1}\right)$ \\
\hline 0 & 0 & 0 \\
\hline 2 & 0.021 & 0.174 \\
\hline 10 & 0.035 & 0.295 \\
\hline 20 & 0.101 & 0.845 \\
\hline 30 & 0.185 & 1.542 \\
\hline 60 & 0.578 & 4.814 \\
\hline 120 & 2.680 & 22.338 \\
\hline 180 & 2.801 & 23.333 \\
\hline
\end{tabular}

The number of transferred electrons during the oxidation of sodium borohydride by C-220 catalyst was calculated at more anodic potential of $0.2 \mathrm{~V}$ using Koutecky-Levich equation as given below

$$
\begin{gathered}
\frac{1}{i}=\frac{1}{i d}+\frac{1}{i k} \\
\frac{1}{i}=\frac{1}{n F A k C_{o}^{*}}+\frac{1}{0.62 n F A D 2 / 3 v-1 / 6 \omega 1 / 2 C_{o}^{*}}
\end{gathered}
$$

Here, $i_{d}$ is the diffusion limiting and $i_{k}$ represents the kinetic current density, $n$ denotes the total number of electrons transferred during the electro-oxidation of $\mathrm{NaBH}_{4}$, ' $A$ ' is the area of electrode used for analysis, ' $F$ ' represents the Faraday constant (96500 C $\left.\mathrm{mol}^{-1}\right)$, ' $\mathrm{k}$ ' is the apparent rate constant $\left(\mathrm{cm} \mathrm{s}^{-1}\right),{ }^{\prime} \mathrm{Co}_{0}{ }^{*}$ 'stand for concentration of $\mathrm{NaBH}_{4}$ used during the measurements $\left(\mathrm{mol} \mathrm{cm}{ }^{-3}\right.$ ), ' $\omega$ ' is the angular rotation (radian s-1 ), ' $v$ ' represents the kinematic viscosity of the solution $\left(1.19 \times 10^{-2} \mathrm{~cm}^{2} \mathrm{~s}^{-1}\right)$ and ' $D$ ' denoted the diffusion coefficient of the electrochemically active species present in the solution $\left(1.6 \times 10^{-5} \mathrm{~cm}^{2} \mathrm{~s}^{-1}\right)$.

The linear sweep polarization curve that presented in the figure $3 c$ (main manuscript) was collected under various rotation speed (100 to $1300 \mathrm{rpm}$ ) to construct the K-L plot using above mentioned equation. From the equation (2) a plot of reciprocal of the current density $v s$. the rotation speed and the obtained graph at various potential is shown below and in revised SI. The obtained slopes and the intercept of the $\mathrm{i}^{-1}$ and $\omega^{-}$ $1 / 2$ was used to calculate the $n$, which come out to be 7.2 at $0.20 \mathrm{~V}$ indicating that $\mathrm{C}$ 220 catalyst exhibiting high affinity towards the oxidation of $\mathrm{NaBH} 4$ under high alkaline conditions. 
Table S2. Represents the number of electrons transferred during the electro-oxidation of $\mathrm{NaBH}_{4}$ by C-220 catalyst using $30 \mathrm{mM}$ of $\mathrm{NaBH}_{4}$ in nitrogen saturated $1 \mathrm{M} \mathrm{NaOH}$.

\begin{tabular}{|l|l|}
\hline \multicolumn{2}{|l|}{ Table S2: No. of electrons calculated from RDE measurements. } \\
\hline Potential (V vs. Hg/HgO) & $\mathbf{n}$ \\
\hline-0.9 & 1.9 \\
\hline-0.12 & 3.4 \\
\hline 0.2 & 1.8 \\
\hline
\end{tabular}

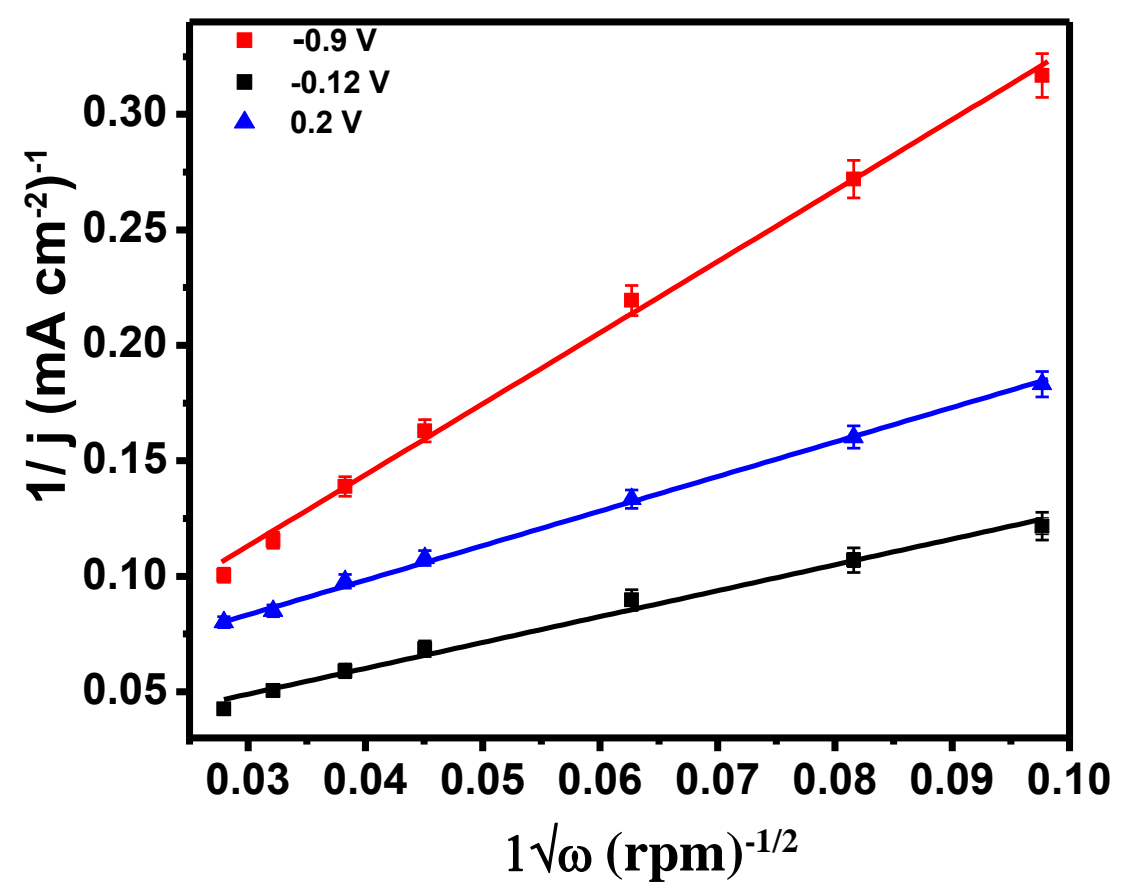

Figure S8. Koutecky-Levich plot extracted from the linear polarization curve (Figure 3c, main manuscript) at various rotation speed ranging from $100 \mathrm{rpm}$ to $1300 \mathrm{rpm}$ under $\mathrm{N}_{2}$ saturated $1 \mathrm{M} \mathrm{NaOH}$ containing $30 \mathrm{mM}$ of $\mathrm{NaBH}_{4}$. 


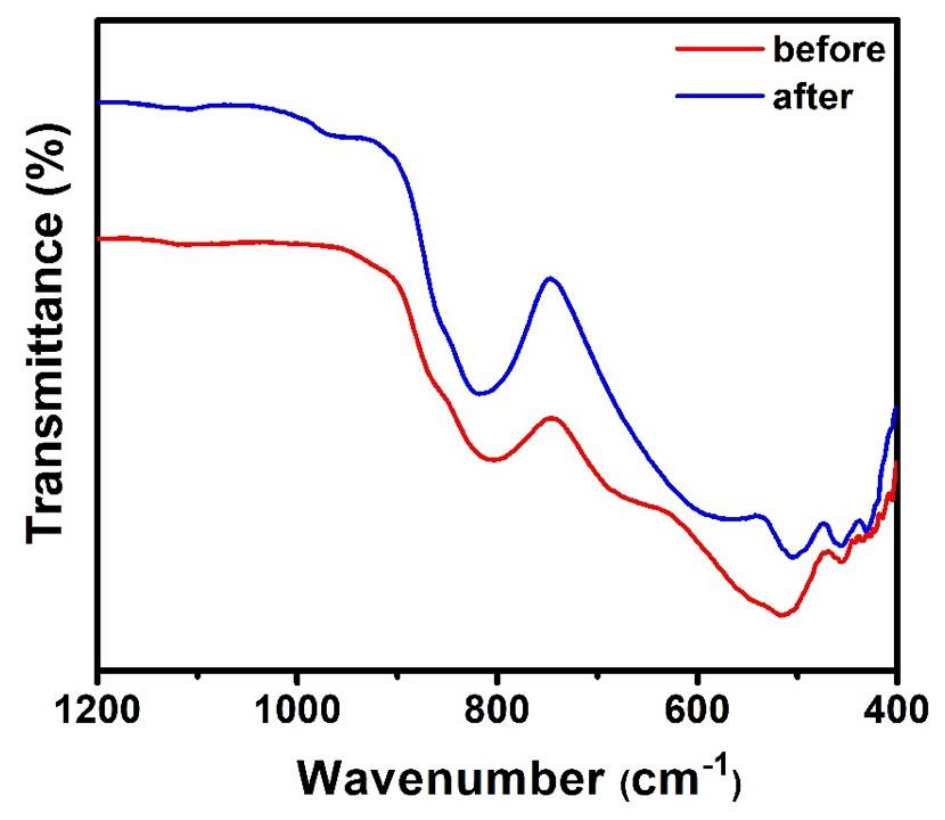

Figure S9. FT-IR spectra of C-220 catalyst both before and after prolonged BOR in $\mathrm{N}_{2}-$ purged $30 \mathrm{mM} \mathrm{NaBH}_{4}$ prepared in $1 \mathrm{M} \mathrm{NaOH}$ electrolyte.

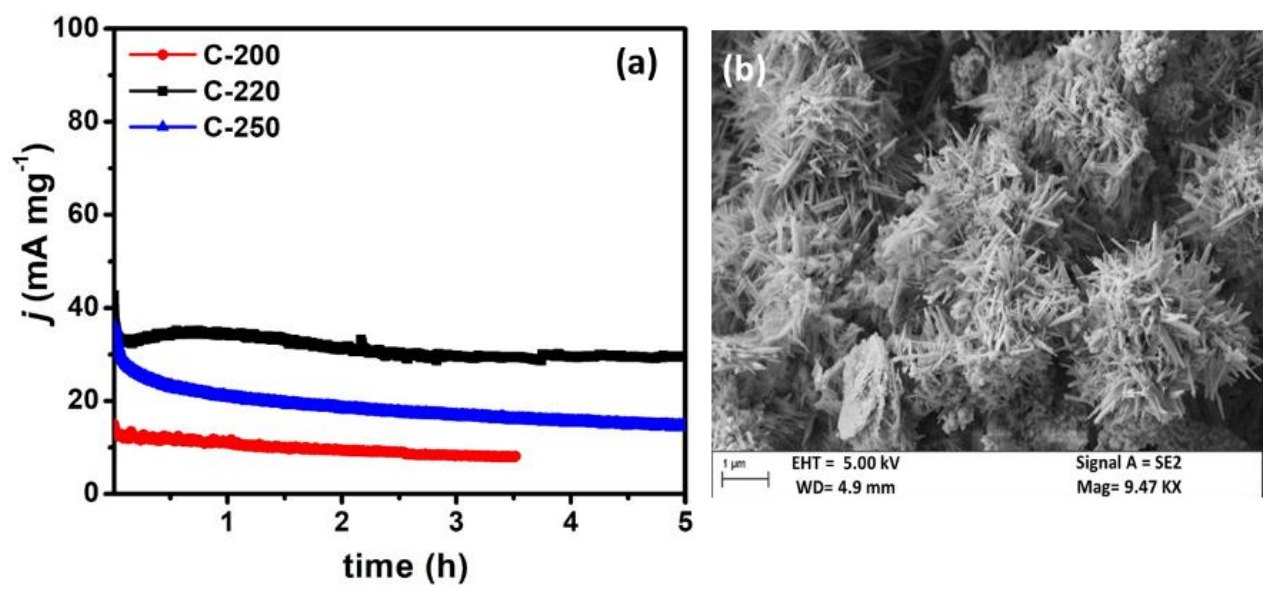

Figure S10. Chronoamperometric stability analysis of all the variants at fixed potential of $-0.7 \mathrm{~V}$ in $\mathrm{N}_{2}$-purged $30 \mathrm{mM} \mathrm{NaBH}_{4}$ in $1 \mathrm{M} \mathrm{NaOH}$ electrolyte; CE: Graphite rod; RE: $\mathrm{Hg} / \mathrm{HgO} / 1 \mathrm{M} \mathrm{NaOH}$. (b) FE-SEM image collected for C-220 variant after prolonged electro-oxidation of $\mathrm{NaBH}_{4}$ under $1 \mathrm{M} \mathrm{NaOH}$ condition. 

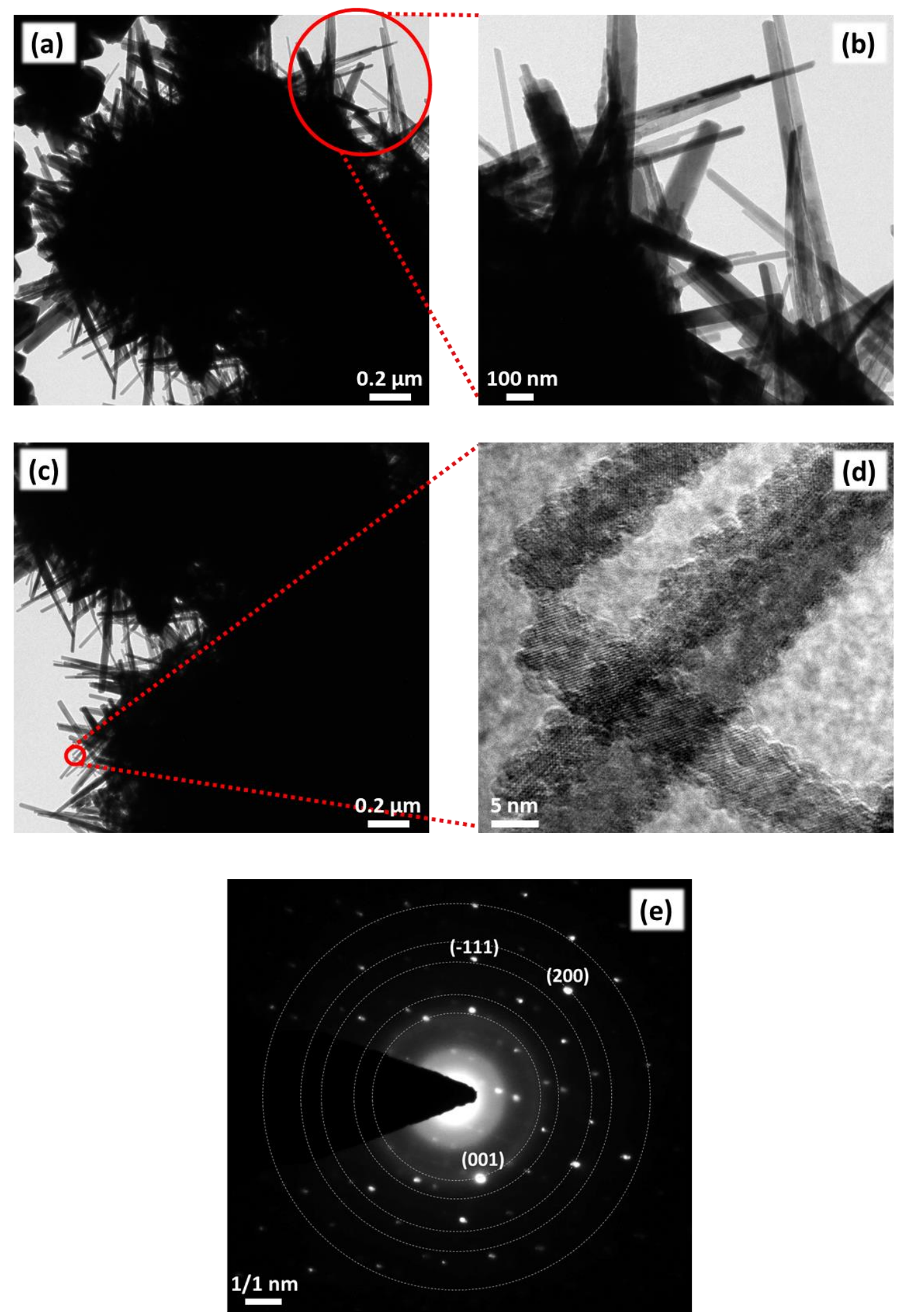

Figure S11. (a-c) TEM and (d) HR-TEM images for C-220 catalyst showing nanoscale structure of urchin-like morphology and (e) SAED pattern for C-220 catalyst. 